\title{
Glass Fertilizers Obtained Using Sewage Sludge ASH Wastes
}

\begin{abstract}
BOGDAN A. MILITARU, COSMIN VANCEA*, RODICA PODE
Politehnica University of Timisoara, Faculty of Industrial Chemistry and Environmental Engineering, 2 Piata Victoriei, 300006, Timisoara, Romania

The sewage sludge ash represents an important waste both in terms of the generated quantities and the phosphorus content. Starting from these premises, the present paper proposes an alternative way to use these ash as vitreous fertilizers. Another waste with potential applicability for this purpose is the sludge from the deep water treatment plants, which has a high iron content, an essential microelement for plants development. The paper addresses two aspects: the kinetic study of the solubilisation process of potassium, phosphorus and iron ions from the obtained fertilizers and their effect on barley plants respectively. The kinetic study using the model of intra particular diffusion revealed the process of ionic solubilisation process in two distinct steps: one slow, speed controlling - diffusion through the glass matrix, and second, faster diffusion through the medium particle boundary. The fertilizing effect, analysed using specific parameters: germination percent, biomass and plantlength, recommends as optimal the composition with the maximum addition of ash.
\end{abstract}

Keywords: sewage sludge ash, phosphate glasses, fertilizers

Sewage sludge is the main waste produced by the municipal waste water plant. The management of this waste had become an important growing issue [1]. In 2010, more than 10 million tons of dried sewage sludge were generated from 27 European Union countries. Moreover, it is expected 13 million tons of sewage sludge to be generated from the 27 European Union countries due to the industrialization and urbanization [2-5]. In all European Union countries directives regarding sewage sludge management are introduced. Classical methods, such as storage, are now being replaced by methods leading to waste stabilization and safe recycling. The most important aim is to promote an ecological management of the sewage sludge.

Many methods regarding the sewage sludge management are presented in the literature: the use of sewage sludge to improve soil quality [6, 7], conventional incineration [8], co-incineration [9], cementing [10], vitrification [11], pyrolysis [8].

One of the most utilised management method is to incinerate the sewage sludge in order to obtain small volumes and to stabilize the sewage sludge. The sewage sludge ash is the waste generated in incineration plants [12] and in preceding years it was observed an increase in quantities produced in European Union countries as a consequence of the investments in the incineration infrastructure [13].

Phosphorus is one of the most important element for human health, industry and agriculture. The main reserve of phosphorus is the phosphate rock [14]. On the other hand, it is known that the phosphate rock will run out in the next 50-100 years [15]. Sewage sludge ash is a richphosphorus material and has a high potential for phosphorus recovery. Therefore, sewage sludge ash is a promising waste in order to capitalize and recover phosphorus in various techniques.

One way to recover phosphorus and other important elements from sewage sludge ash is as phosphate agriglasses used as fertilizers. Glass fertilizers are advanced and controlled released fertilizers made of glass matrices $[16,17]$. This fertilizers include in their composition macroelements ( $\mathrm{K}, \mathrm{P}, \mathrm{Mg}, \mathrm{Ca}$ ) and also microelements ( $\mathrm{Fe}$, $\mathrm{Mn}, \mathrm{Zn}, \mathrm{B}, \mathrm{Cu}$ ) useful for the development of the plants. A slow and a controlled dissolution of this type of fertilizer provides phosphorus and other elements to plant uptake for a long period of time [18]. Using these fertilizers, the dosage requirements are lowered, the efficiency is improved and the problems regarding environmental pollution are minimized [19].

The present paper proposes an alternative way to recover the sewage sludge as agriglasses. The chemical activity of the synthesized products, namely the kinetics of solubilisation of potassium, phosphorus and iron ions, having major impact on the plant development, was studied. The influence of the ash content and the fertilizer dose and granulometry on the barley crops was monitored, the optimum composition being identified.

\section{Experimental part \\ Sample preparation}

The sewage sludge used in this study was collected from a municipal wastewater plant from Timis County, Romania. The sewage sludge was dried at $105{ }^{\circ} \mathrm{C}$ for 20 hours and then calcinated $850{ }^{\circ} \mathrm{C}$ for 3 hours using a Nabertherm B180 oven. The resulted sewage sludge ash was milled and mineralized with aqua regia in order to determine the concentration of the main elements $(P, K$, $\mathrm{Na}, \mathrm{Fe}$ etc.) as presented elsewhere [20]. The concentrations of phosphorus and iron were determined through molecular absorption spectrometry using a Hach Lange DR 3900 and DR 2800 spectrometers. The other elements were determined through inductively coupled plasma mass spectrometry (ICP-MS) using a Perkin Elmer NexION 350X spectrometer.

Another waste used in this study is the sludge collected from a drinking water treatment plant. This sludge results from the sand washing process used in the iron removing process at a groundwater treatment plant. Before use, the sludge was calcinated at $750{ }^{\circ} \mathrm{C}$ for 6 hours. This waste is a source of iron, manganese and calcium, it's chemical composition, determined by $X$ ray fluorescence using a Niton XL 3 analyzer was: $83 \% \mathrm{Fe}^{3+}, 10.03 \% \mathrm{Mn}^{2+}$ and $5.41 \%$ $\mathrm{Ca}^{2+}$.

Besides these two wastes, in order to obtain the glass fertilizers, the following reagents were added: $\left(\mathrm{NH}_{4}\right)_{2} \mathrm{HPO}$, $\mathrm{K}_{2} \mathrm{CO}_{3}$ and $\mathrm{CuO}$. All the reagents are of analytical ${ }^{2}$ grade

* email: cosmin.vancea@upt.ro, Phone: +40740193879 


\begin{tabular}{|l|c|c|c|c|c|}
\hline Sample & C1 & C2 & C3 & C4 & C5 \\
\hline $\begin{array}{l}\text { Sewage sludge ash } \\
\text { [\% weight] }\end{array}$ & 5.08 & 7.69 & 10.35 & 13.05 & 15.68 \\
\hline
\end{tabular}

Table 1

SEWAGE ASH CONTENT IN THE STUDIED GLASS FERTILIZERS

\begin{tabular}{|l|c|c|c|c|c|}
\hline \multirow{2}{*}{ Oxide } & \multicolumn{5}{|c|}{ Sample } \\
\cline { 2 - 6 } & $\mathbf{C l}$ & $\mathbf{C 2}$ & $\mathbf{C 3}$ & $\mathbf{C 4}$ & $\mathbf{C 5}$ \\
\hline $\mathrm{SiO}_{2}$ & 9.74 & 14.03 & 18.00 & 21.67 & 25.08 \\
\hline $\mathrm{P}_{2} \mathrm{O}_{5}$ & 45.25 & 41.47 & 38.01 & 34.79 & 31.79 \\
\hline $\mathrm{CaO}$ & 2.23 & 2.90 & 3.52 & 4.09 & 4.62 \\
\hline $\mathrm{Fe}_{2} \mathrm{O}_{3}$ & 3.65 & 3.50 & 3.37 & 3.25 & 3.14 \\
\hline $\mathrm{Na}_{2} \mathrm{O}$ & 0.13 & 0.18 & 0.22 & 0.27 & 0.31 \\
\hline $\mathrm{MgO}^{2}$ & 0.48 & 0.71 & 0.91 & 1.08 & 1.25 \\
\hline $\mathrm{K}_{2} \mathrm{O}$ & 37.28 & 35.81 & 34.45 & 33.19 & 32.02 \\
\hline $\mathrm{Al}_{2} \mathrm{O}_{3}$ & 0.48 & 0.69 & 0.88 & 1.05 & 1.22 \\
\hline $\mathrm{MnO}$ & 0.73 & 0.67 & 0.62 & 0.57 & 0.52 \\
\hline $\mathrm{CuO}_{2}$ & 0.01 & 0.01 & 0.01 & 0.01 & 0.03 \\
\hline $\mathrm{ZnO}$ & 0.01 & 0.01 & 0.01 & 0.03 & 0.02 \\
\hline
\end{tabular}

Table 2

OXIDIC COMPOSITION [MOL \%] OF THE OBTAINED GLASSES

used for the analytical methods. The sewage sludge amount vitrified as agriglasses is presented in table 1.

Table 2 presents the oxidic composition of the obtained glasses.

The precursor materials were weighed, mixed together and then loaded in porcelain crucibles. The melting process was conducted at $1000^{\circ} \mathrm{C}$ for 90 min using a Nabertherm HTC08/16 electric furnace. The vitrification process in this economically advantageous conditions led to very viscous melt for sample $\mathrm{C} 5$, which was difficult to process, therefore it was excluded from further investigations.

The glasses (C1-C4) were milled and sieved, two fractions having particle diameter between $d<0.25$ and $0.25<\mathrm{d}<0.80 \mathrm{~mm}$ respectively, were selected for this study.

\section{Chemical activity}

The chemical activity of the obtained vitreous fertilizers simulates the action of organic compounds released by the plant roots [21]. The samples were introduced into $2 \%$ acid citric solution for $6,24,30,48,54$ and 72 hours, using a solid:liquid ratio of $1: 100$ at $25^{\circ} \mathrm{C}$. The concentration of $\mathrm{K}$, $\mathrm{P}$ and $\mathrm{Fe}$, leached after the considered times were determined with the same techniques as described before. The $\mathrm{pH}$ was determined using a Mettler Toledo $\mathrm{pH}$-meter.

\section{Plants experiments}

A pot experiment was conducted in order to evaluate the influence of the obtained agriglasses (C1-C4) with different granulations on barley (Hordeum vulgare L.). For this purpose, parallel soil samples were seeded with the same number of seeds ( 20 seeds). The amount of fertilizer was $0.01,0.03,0.06$ and $0.08 \mathrm{~g} / \mathrm{cm}^{2}$ corresponding to 0.5 , $1.0,2.0$ and $3.0 \mathrm{~g}$ of agriglass, for all the four compositions and both granulometric fractions. After 28 days the harvested plants were subjected to the following determinations: germination percentage, average total plant and biomass.

\section{Results and discussions}

Chemical activity

The ions dissolution kinetics for the investigated vitreous fertilizers are presented in fig.1.
Regardless of the glass samples composition, the finer granulometric fraction $(\mathrm{d}<0.25 \mathrm{~mm}$ ) solubilizes in a higher percentage compared to the coarse one $(0.8<d<0.25$ $\mathrm{mm})$.

For both granulometric fractions, a decrease of the solubility of ions studied from sample $\mathrm{C} 1$ to $\mathrm{C} 4$ with the increase of the ratio $\mathrm{M}_{2} \mathrm{O} / \mathrm{P}_{2} \mathrm{O}_{5}$ was observed, phenomenon mentioned in literature [23].

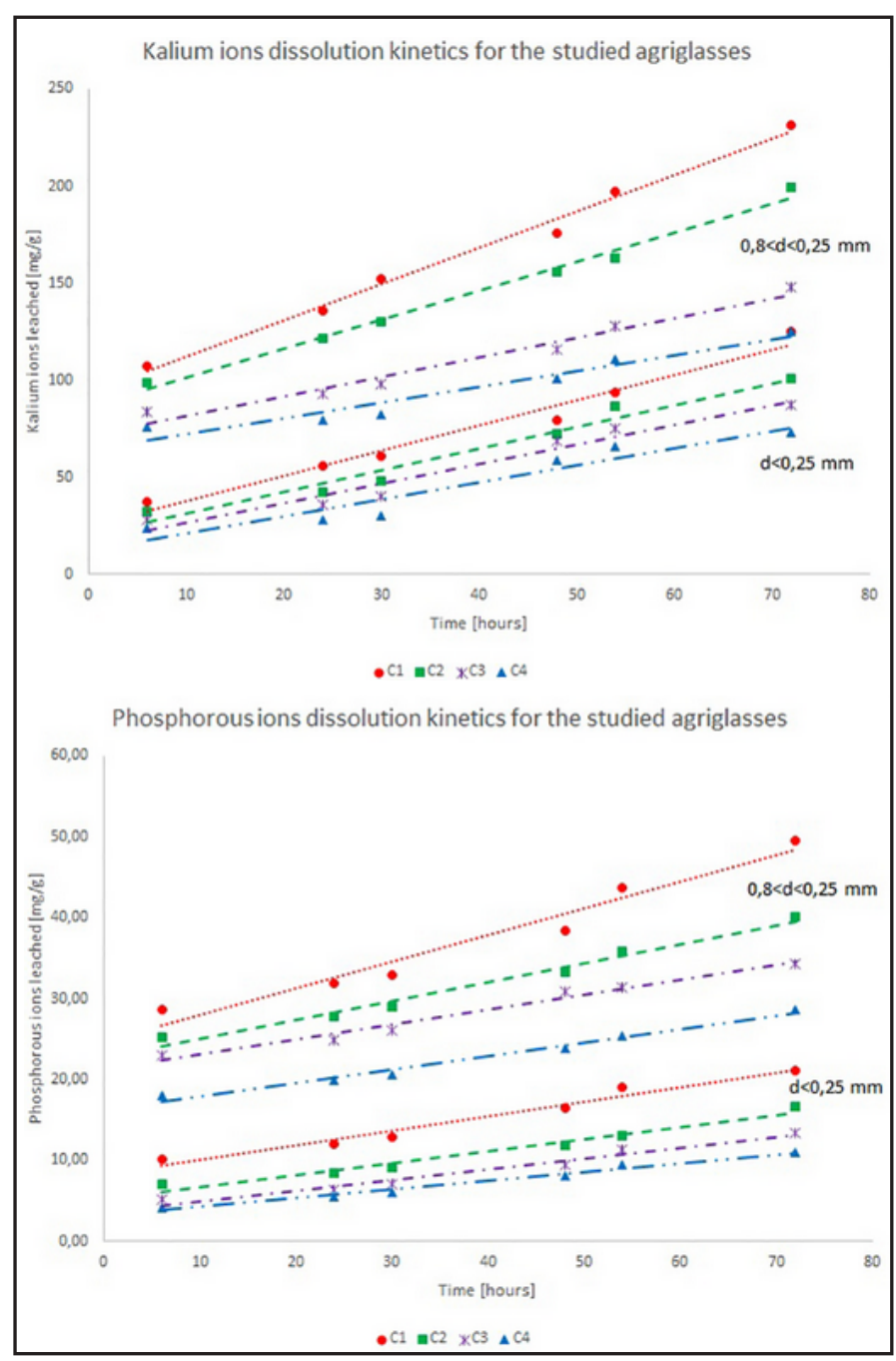




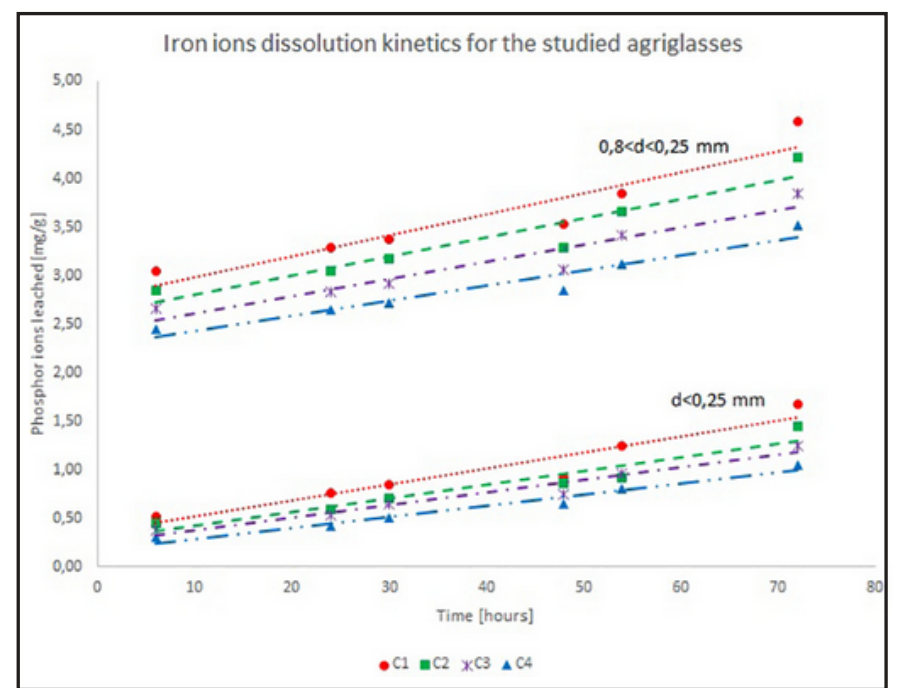

Fig. 1. Kinetics of ions dissolution from the studied glasses

For the interpretation of the kinetic data regarding the leaching of potassium, phosphorus and iron ions from the vitreous phase in the $2 \%$ citric acid solution, the intraparticle diffusion model was used [23, 24].

The equation can be described as: [25]:

$$
q_{t}=k_{t} t^{1 / 2}+C
$$

where $k_{\text {, }}$ is the intraparticle diffusion rate constant $\left(\mathrm{mg} \mathrm{g}^{-1}\right.$ $\mathrm{h}^{-1 / 2}$ ) and $C$ is the intercept, related to the thickness of the boundary layer. The larger $\mathrm{C}$ implies the greater effect of the boundary layer [26].
The leached ions amount per gram of glass $\left(q_{1}\right)$ was calculated using Eq. (2)

$$
q_{t}=\frac{v\left(c_{0}-c_{t}\right)}{m}
$$

where $C_{\text {ond }}$ an $C_{t}$ are initial concentration and the concentration corresponding to a considered time $t$ $\left(\mathrm{mgL}^{-1}\right), V$ is citric acid solution volume $(\mathrm{L}), m$ is the mass of vitreous fertilizer ( $\mathrm{g}$ ).

According to Eq. (1), if the dissolution mechanism follows the intraparticle diffusion model, the plot of $q_{t} v s$. $\mathrm{t}^{1 / 2}$ should be linear, slope $\mathrm{k}_{\mathrm{t}}$ and intercept $\mathrm{C}$ will be obtained using linear fitting analysis.

The obtained data are presented in fig. 2 for the three ions analyzed and the two particles dimensional ranges.

Regarding the potassium ion, for both granulometric fractions, the graphical representation $q_{t}=f\left(t^{1 / 2}\right)$ shows a double linearity relation indicating that more than one process influence the ion leach. In our opinion, the first stage corresponds to the diffusion through the vitreous network and the second stage to the diffusion through the interface particle - medium. For all the 4 compositions, the linear regression slope corresponding to the first diffusion stage is significantly lower compared to that for the 2nd stage, indicating that the rate-controlling stage is the intraparticle diffusion.

A similar behavior was recorded for phosphor and iron ions suggesting that the leaching process can be described by a two stage diffusion model where intraparticle diffusion is rate-controlling.

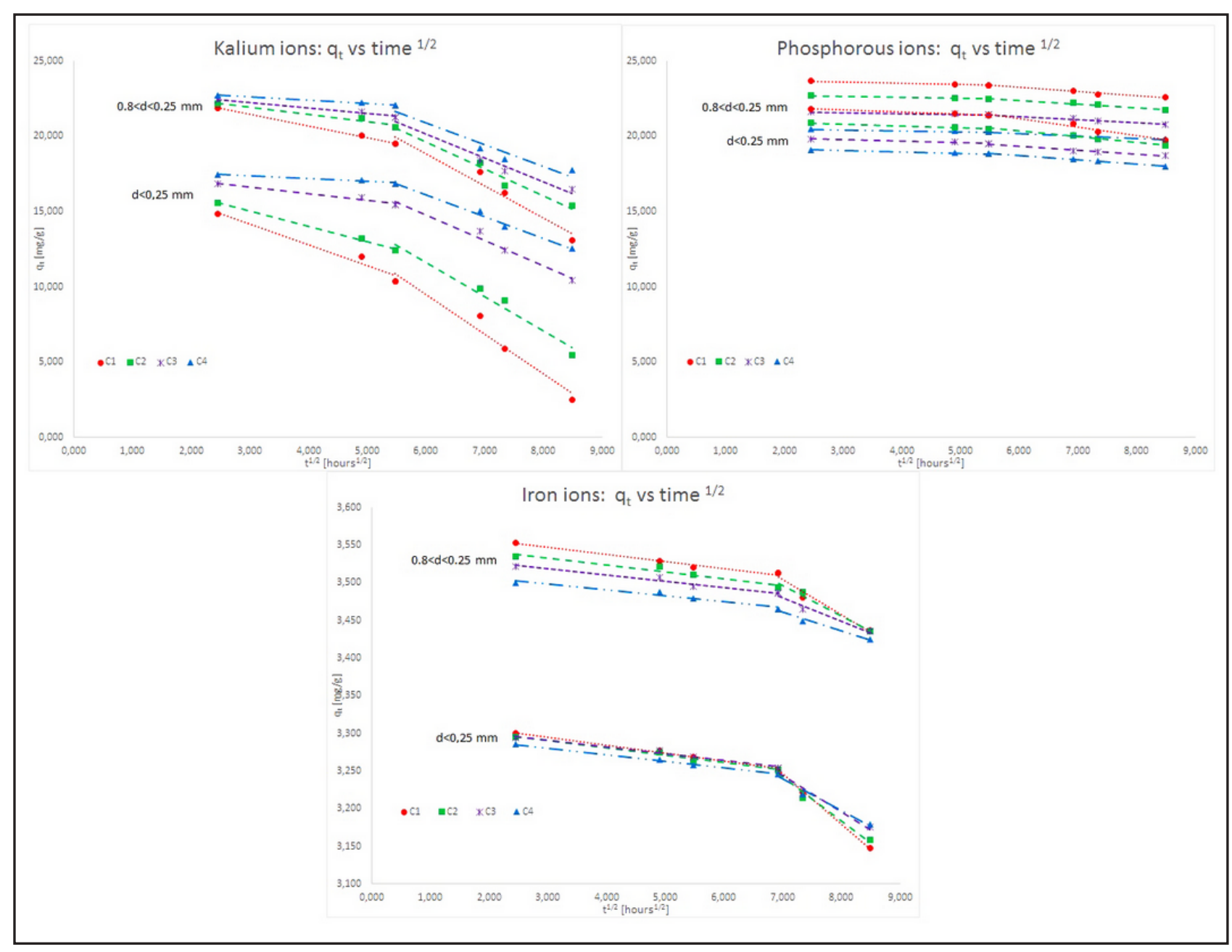

Fig. 2. Intraparticle diffusion model plot for the investigated glasses 


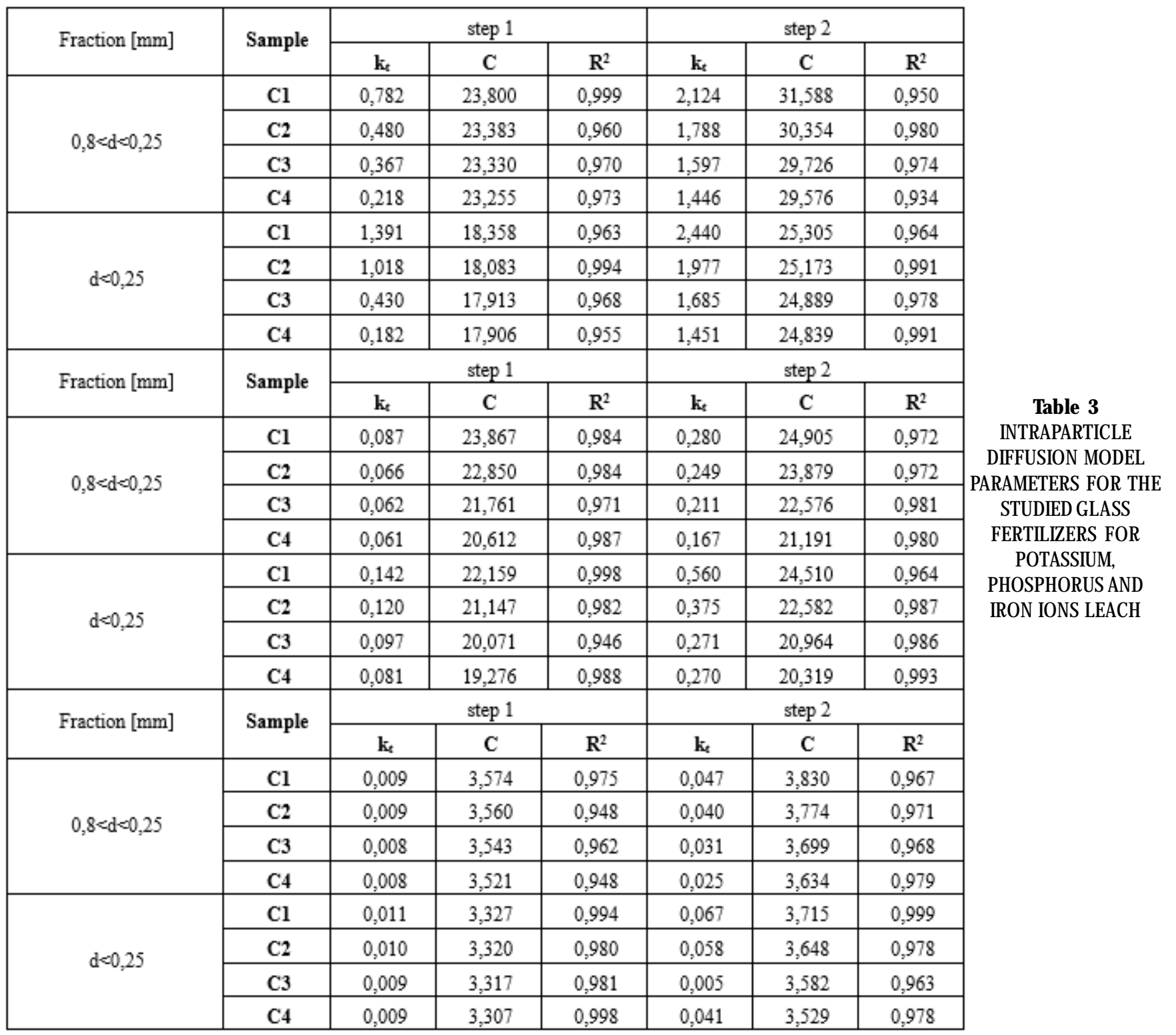

The values of $k_{t} C$ and $R^{2}$ obtained from the linear regression analysis are presented in table 3.

The R-squared values, higher than 0.9 validate the proposed intraparticle model.

The intraparticle diffusion rate constant $k_{t}$ values lower in the first step comparing to the second step can be explained by the fact that intraparticle diffusion is a slower process compared to diffusion through the interface.
The $C$ values, relates to the thickness of the boundary layer, are higher for the second step of the process for all the glasses, indicating the influence of the interface leaching mechanism.

\section{pHevolution}

Figure 3 illustrates the $\mathrm{pH}$ evolution for the leaching citric acid solution for the considered time.

The ions dissolution from the studied glasses generates small changes of $\mathrm{pH}$, ranging from 2.4 to 2.6 after $72 \mathrm{~h}$. The

pH vs. time

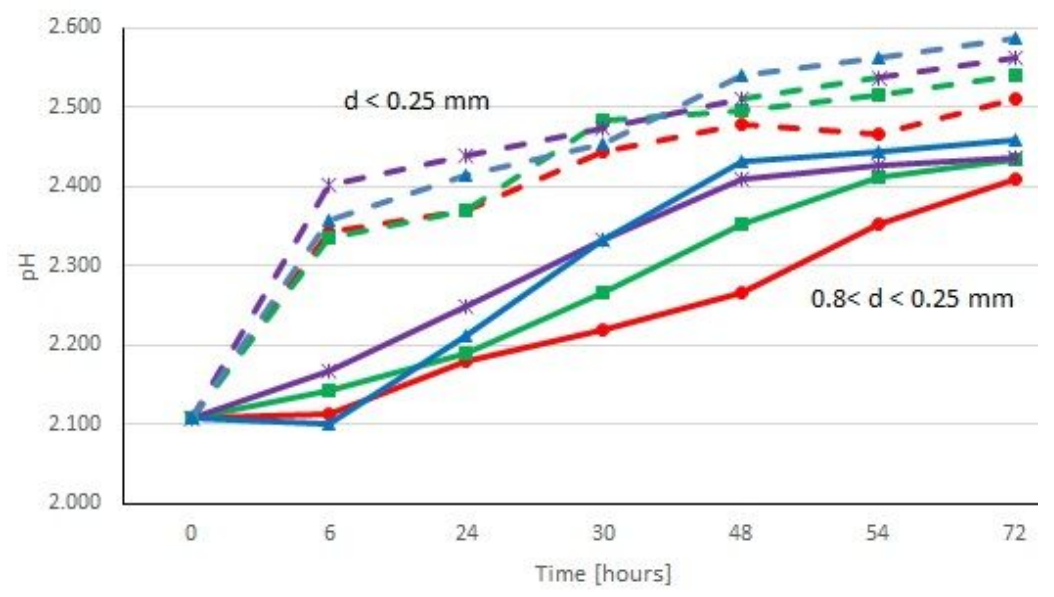

Fig. 3. Variation of $\mathrm{pH}$ versus dissolution time 


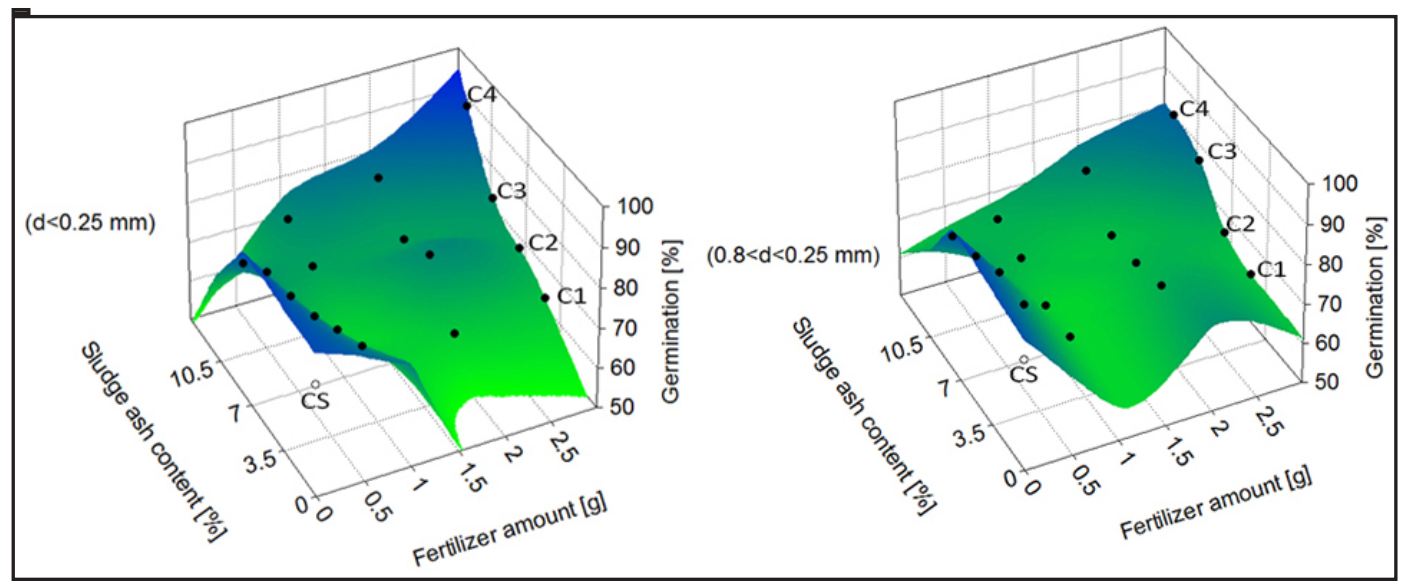

Fig. 4. The effect of sludge ash content and fertilizer dose upon the plants germination

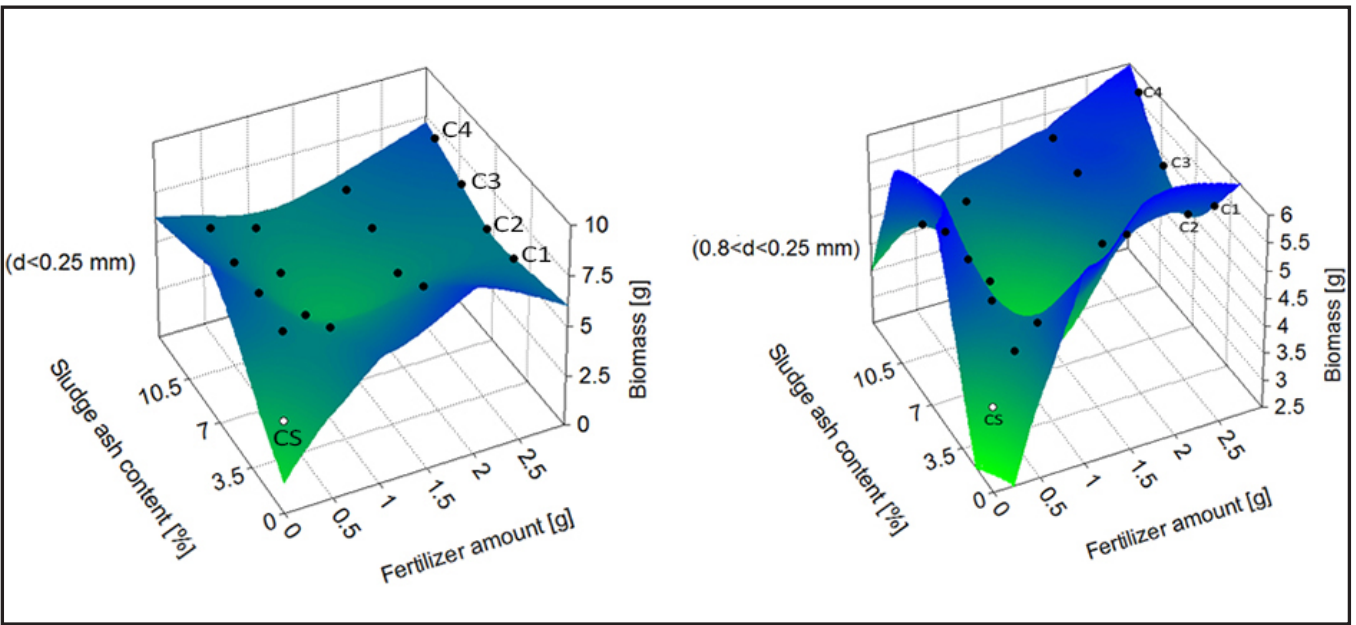

Fig. 5. The effect of sludge ash content and fertilizer dose upon the plants biomass
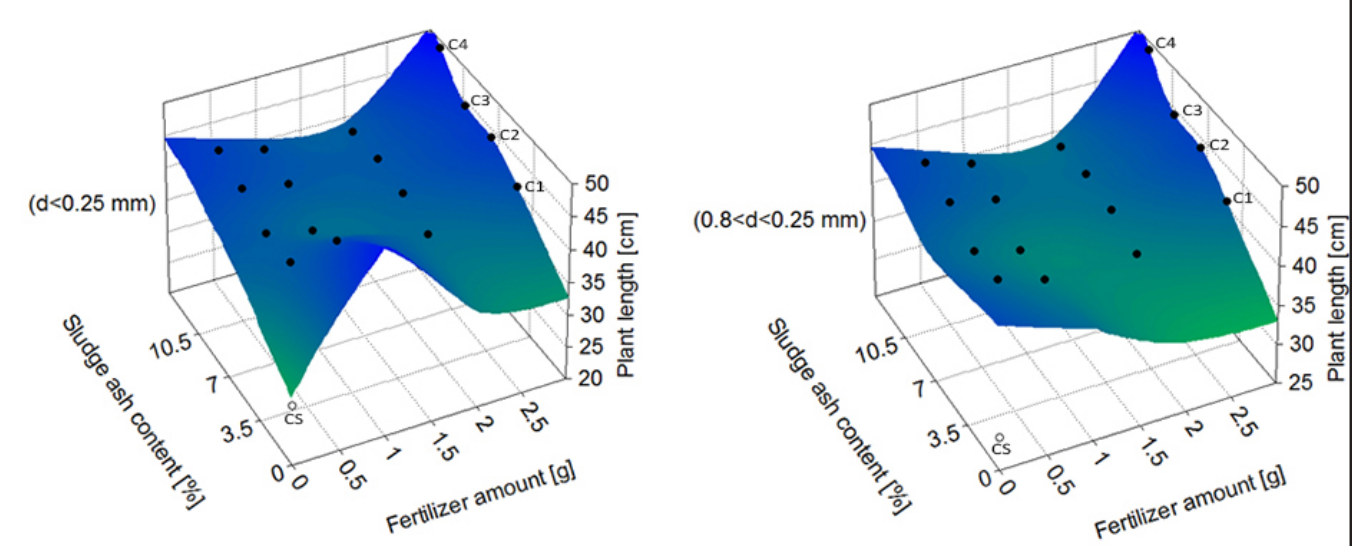

Fig. 6. The effect of sludge ash content and fertilizer dose upon the plants length

$\mathrm{pH}$ growth in the considered time interval for all the samples is generated by the massive potassium ions dissolution compared to phosphorous ions leached.

Increasing the grain size leads to a lesser ions dissolution and therefore to less important growths of the $p \mathrm{H}$, due to the decrease of the glass specific surface in contact with the citric acid solution.

\section{Effects on plants}

The effect of the obtained glass fertilizers on the barley was studied using the germination percent, biomass and plant length as characterisation parameters.

Figure 4 presents the influence of the sludge ash content and the fertilizer dose upon the plants germination percent for both granulometries.

Both considered parameters have a significant positive influence upon plants germination, the experimental values being higher than the germination percent for the control sample (CS), without agriglass. The best results, for both fertilizer grain diameters, were obtained for sample C4 using the highest dose, $0.08 \mathrm{~g} / \mathrm{cm}^{2}(3.0 \mathrm{~g})$.
The effect of the sludge ash content and the fertilizer dose upon the plants biomass is illustrated in fig. 5 .

All the studied glass fertilizers have a beneficial effect upon the barley biomass after 28 days, the measured values being higher that the control sample (CS) biomass for both agriglasses granulometries. The higher biomass was obtain using $0.08 \mathrm{~g} / \mathrm{cm}^{2}(3.0 \mathrm{~g})$ of sample $\mathrm{C} 4$ glass composition.

The influence of sludge ash content and fertilizer dose on the plants length is presented in fig. 6.

The positive effect of the studied agriglasses upon the plants length was observed for all the investigated compositions at both granulometries, sample C4 used in the highest dose being the most effective.

The results above recommend sample $\mathrm{C} 4$ as the optimum composition, used in the dose of $0.08 \mathrm{~g} / \mathrm{cm}^{2}$.

\section{Conclusions}

In the present paper, the possibility of salvage the sewage sludge ash from the municipal waste water plant and the sludge from iron removing process at a groundwater treatment plant as vitreous fertilizers was approached. 
Five compositions containing different amount of sewage sludge ash embedded in the glass matrix were synthesized. Too much sludge ash (sample C5) leads to an incomplete vitrified meltusing the proposed economically advantageous synthesis conditions.

The chemical activity and the fertilizing efficiency on barely plants was studied for the considered glass compositions.

Kinetic study of the solubilisation of potassium, phosphorus and iron ions, important in plant nutrition, indicated the favourable effect of the fineness of grinding on the release of the ions from the vitreous matrix.

For the interpretation of kinetic data, the intraparticle diffusion model was used. Two distinct stages of the ion solubilisation process were highlighted: the first through intraparticle diffusion and the second through diffusion through the particle boundary. For all the studied compositions, the rate-controlling stage is the intraparticle diffusion. The intraparticle diffusion model parameters for potassium, phosphor and iron ions leach were calculated.

The effect of the synthesized vitreous fertilizers on the barley plant was evaluated using the specific parameters: germination percent, biomass and plants length. The results highlighted their favorable effect on the plants development compared to the control sample.

Based on the experimental results for the considered specific plant growth parameters, sample C4 dosed for $0.08 \mathrm{~g} / \mathrm{cm}^{2}$, was identified as optimal.

Acknowledgements:This work was conceived within the framework of the Doctoral School of Politehnica University of Timisoara.

\section{References}

1.BARTfOMIEJ , M.C., JACEK, N, PIOTR, K., J. Clean. Prod., 90, 2015, p. 1.

2.J ONG, M.J., JEONG, I.O., JIN, G.K., HYUN, H.K., YOUNG, K.P., EILHANN, E.K., Environ. Int., 131, 2019, p. 105035.

3.KELESSIDIS, A., STASINAKIS, A.S., Waste Manag., 32, 2012, p. 1186. 4.KACPRZAK, M., NECZAJ , E., FIJ AUKOWSKI, K., GROBELAK, A., GROSSER A., WORWAG, M., RORAT, A., BRATTEBO, H., ALMAS, A., SINGH, B.R. Environ. Res., 156, 2017, p. 39.
5.DimA, C., BADANOIU, A., STOLERIU, S., LUCA, D., Rev. Chim. (Bucharest), 70, no. 5, 2019, p.1750.

6.MILLS, M., PEARCE, P., FARROW, J., THORPE, R.B., KIRKBY, N.F., Waste Manag. 34, 2014, p.185.

7.PURDEA, L., RUSANESCU, C.O., TUCUREANU, M.C., Rev. Chim. (Bucharest), 70, no. 6, 2019, p.1967.

8.SAMOLADA, M., ZABANIOTOU, A., Waste Manag. 34, 2014, p. 411. 9.DONATELLO, S., CHEESEMAN, C.R., Waste Manag. 33, 2013, p. 2328.

10.CHEN, M., BLANC, D., GAUTIER, M., MEHU, J., GOURDON, R., Waste Manag. 33, 2013, p. 1268.

11.BERNARDO, E., DAL MASCHIO, R., Waste Manag. 31, 2011, p. 2245. 12.WDOWIN, M., FRANUS, M., PANEK, R., BANDURA, L., FRANUS, W., Clean. Technol. Environ. 17 (3), 2015, p. 819.

13.IOPPOLO, G., CUCURACHI, S., SALOMONE, R., SAIJA, G., SHI, L., Sustainability 8 (2), 2016, p. 180.

14.SMOL M., KULCZYCKA J., KOWALSKI Z., J. Environ. Manag., 184, 2016, p. 617.

15.CORDELL, D., DRANGERT, J., WHITE, S., Glob. Environ. Chang. 19, 2009, p. 292.

16.HAZRA, G., DAS, T., GJSFR-B, 14(4), 2014.

17.LEONARD, I., MIHALACHE, M., SCAETEANU, G.V., MADJAR R.M., POPOVICI, D.R., Rev. Chim. (Bucharest), 69, no. 5, 2018, p.1166.

18.IVANENKO, V., KARAPETYAN, G., LIPOVSKII, A., MAKSIMOV, L., RUSAN, V., TAGANTSEV, D., TATARINTSEV, B., FLECKENSTEIN, J., SCHNUG, E., Landbauforschung-Ger, 4(57), 2007, p. 323.

19.OUIS, M. A., ABD-ELADL, M., ABOU-BAKER, N.H., Silicon, 10(2), 2018, p. 293.

20.MILITARU, B.A., PODE, R., MANEA, F., LINUL, P.A., Rev. Chim. (Bucharest), 70, no. 1, 2019, p. 133.

21.GORLACH, E., MAZUR, T., Soil chemistry 2001, p. 8. Warsaw: Polish Scientific Publishers.

22.LEE, H.K., HWANG, S.J ., KANG, W.H., Mater. Sci. Forum, 486-487, 2005, p. 407.

23.SIMONIN, J.P., BOUTÉ, J, Rev Mex Ing Quim, 15 (1), 2016, p.161.

24.NETHAJI, S., SIVASAMY, A., MANDAL, A. B., Int. J. Environ. Sci. Technol., 10, 2013, p. 231.

25.HAN, X., WANG, W., MA, X., Chem. Eng. J., 171, 2011, p. 1.

26.VIMONSES, V., LEI, S., JIN, B., CHOW, C.W.K., SAINT, C., Appl. Clay Sci., 43, 2009, p. 465.

$\overline{\text { Manuscript received: } 14.10 .2019}$ 